\title{
Inovações e pesquisa na indústria pesqueira na Amazônia
}

Oriana Almeida - Professora do Núcleo de Altos Estudos Amazônicos da UFPA.

Sérgio Rivero - Professor do Departamento de Economia da UFPA.

Scheyla Androczevecz - Engenheira Química. Mestre em Tecnologia Ambiental pelo Imperial College.

Nazareno Araújo - Professor de economia da FEPESCA-UFPA Braganca.

\section{Resumo}

Este trabalho tem o objetivo de analisar a introdução de novas espécies e novos produtos de pescado no mercado, que possam reduzir a pressão da pesca sobre as espécies preferenciais. Aproximadamente 30 entrevistas foram feitas com pesquisadores de instituições e frigoríficos. Desse total, 12 eram instituições de pesquisa, e somente seis tinham pesquisas sobre o tema novas espécies e inovações tecnológicas no setor pesqueiro, entre elas apenas duas tiveram o resultado das pesquisas adotado pelo setor industrial. No setor industrial 18 frigoríficos foram entrevistados, e destes 12 introduziram novas espécies e 12 introduziram novos produtos ao longo dos últimos quatro anos (mais de uma resposta por frigorífico). Em relação ao desenvolvimento e aplicação de novas tecnologias no setor pesqueiro os resultados mostraram que tanto as instituições de pesquisa quanto os frigoríficos têm papéis importantes. É preciso que ambos trabalhem em conjunto, com base nas necessidades do setor, procurando definir linhas de pesquisa conjuntas com produtos viáveis economicamente para que o setor possa vir a se beneficiar dessas pesquisas e aprimorar seu desenvolvimento.

\section{Palavras-chave}

Indústria pesqueira; novas espécies; novos produtos; Amazônia.

\section{Abstract}

The aim of the present study is to analyse the introduction of new species and new products into the market in order to help reduce pressure on the main species exploited. Thirty interviews were carried out at research institutes and fish processing plants. Among these, 12 were research institutions, six of which did research on new species and technological innovations in the fishery industry, and only two reported the results of their research adopted by the industrial sector. Among the 18 fishing processing plants where interviews were held, 12 had introduced new species and 12 had introduced new products in the last four years (more the one response per factory). Regarding the development and use of technology in the fish processing plants, the results demonstrate that both the institutions and processing plants play important roles, but have little articulation. It is important, however, that both work together towards the needs of the industry in an attempt to define lines of research with economically viable products from which the industry can benefit and improve its development.

\section{Keywords}

Fishery Industry; New Species; New Products; Amazon. 


\section{INTRODUÇÃO}

O volume mundial total de pesca em 2005 atingiu o valor de 142,6 milhões de toneladas (FAO, 2007). Desse total, cerca de 75\% é produzido para consumo humano, o restante é destinado à fabricação de farinha de peixe e de óleos. No Brasil, a Amazônia tem-se tornado o principal produtor de pescado (IBAMA, 1998, 1999, 2000a, 2000b, 2001, 2003, 2005), e a oferta de pescado vem principalmente da captura de pescado pela frota artesanal (ALMEIDA; MCGRATH; RUFFINO, 2001; ALMEIDA; LORENZEN; MCGRATH, 2003; BATISTA, 1998; ISAAC; MILSTEIN; RUFFINO, 1996; PETRERE, 1998a, 1978b, ALMEIDA et al. 2006). Estimase que aproximadamente 100.000 pescadores (ALMEIDA; MCGRATH; RUFFINO, 2001; BATISTA, 1998; BAYLEY; PETRERE, 1989) atuam na pesca na Amazônia; as atividades da pequena pesca familiar e da frota comercial são responsáveis pela maior geração de emprego do setor (ou mão-de-obra ocupada), e a indústria de processamento é uma importante fonte de renda (ALMEIDA et al., 2003; MCGRATH et al., 1993).

De acordo com as projeções feitas para o consumo mundial de pescado, a produção crescerá com base na aqüicultura, enquanto a produção pesqueira, a partir dos recursos naturais, permanecerá estável. Assim, o abastecimento para atender a essa demanda crescente terá de ser feito por meio da aqüicultura.

Dadas as projeções de consumo crescente, uma outra forma de aumentar a produção consiste na introdução de novas espécies, na redução de perdas durante a captura e no processamento.

$\mathrm{Na}$ Amazônia, as perdas durante o processo de pesca e de processamento são imensas. Perdas ocorrem nas embarcações em razão do mau acondicionamento, do uso inadequado do gelo e da contaminação. Não há estudos detalhados sobre o tema, mas estima-se que as perdas sejam bastante significativas nas embarcações. Outra fonte grande de perda é em relação à fauna acompanhante, especialmente relativo à pesca da frota industrial no estuário. Estimase que, na pesca do camarão, uma das pescarias mais importantes da Amazônia em termos de valor econômico agregado, a fauna acompanhante descartável chega a ser cinco vezes o total de camarão capturado (ISAAC, 1998). Também é alto o descarte na pesca da piramutaba (Brachyplatystoma vaillantii). Na década de 60, os descartes chegavam a $60 \%$ do volume capturado de piramutaba, tendo atualmente caído para 12\%, principalmente em razão da redução da abundância do recurso natural (ISAAC, 1998).

Por causa da grande distância de viagem para a pesca dessas espécies e do tamanho limitado dos barcos industriais que atuam no estuário amazônico, a fauna de baixo valor econômico não é aproveitada. 
A situação da fauna acompanhante é um grave problema na Amazônia, como no mundo, onde estima-se um descarte de 27 milhões de toneladas de espécies de baixo valor (FAO, 2002).

A perda também ocorre de forma intensa no processamento. Por causa da abundância inicial do pescado na Amazônia, há pouco registro de iniciativas para o aproveitamento de subprodutos no processamento. José Maria Damasceno (informação verbal) calculou que as perdas nos processos de filetagem ficam entre 40 e $70 \%$ do peso do pescado inteiro. Essas perdas podem ser reduzidas consideravelmente com a introdução de novos processos de aproveitamento.

Com o crescimento mundial da demanda, o pescado tem deixado de ser um produto de baixo valor para atingir altos valores nos mercados, e a expectativa de redução dos estoques elevará mais ainda os seus preços. A tendência é que os mercados para produtos de valores agregados maiores sejam ampliados, e que o setor desenvolva mercado para novas espécies não exploradas. Paralelamente, espera-se que haja inovação contínua nos produtos e na apresentação dos produtos derivados da pesca.

Neste trabalho, analisamos a pesquisa e introdução no mercado de novas espécies e de novos produtos de pescado que reduzem a pressão da pesca sobre as espécies preferenciais. Isso é feito a partir do levantamento de informações em instituições de pesquisa e em frigoríficos que adotem alternativas de utilização de novas espécies e de novos produtos no setor pesqueiro.

\section{Metodologia}

Foram contactadas 37 instituições com possíveis pesquisas associadas ao setor pesqueiro e seus técnicos foram entrevistados informalmente; entre essas instituições foram selecionadas 12 que incluem organizações não-governamentais que realizam pesquisa sobre o manejo dos recursos regionais, e duas organizações baseadas na cidade de Letícia. Os tópicos das entrevistas eram: o tamanho da unidade de pesquisa, em termos de número de pesquisadores envolvidos e de volume financeiro disponível; o tamanho do grupo específico dedicado à pesquisa de novos produtos e novas espécies; a qualificação dos recursos humanos e os temas estudados.

Foram obtidas informações sobre o histórico das instituições em termos de pesquisa na área de pescado, como os tipos e resultados dos estudos anteriores, o número de pesquisas adotadas pelo setor produtivo e os fatores que interferiram nessa adoção. Apesar da grande quantidade de estudos sobre ecologia e biologia pesqueira de várias instituições, consideraram-se somente as unidades de pesquisas que envolviam desenvolvimento de produtos, análise de novas espécies para uso comercial e pesquisas estratégicas de manejo pesqueiro. 
Também foram realizadas entrevistas semi-estruturadas (questionários com questões abertas e fechadas), em 20 frigoríficos do estado do Amazonas e Pará sobre a introdução de novas espécies e produtos. Nos frigoríficos, as perguntas eram sobre os estudos anteriores e as em andamento nas empresas, sobre como as empresas tomavam conhecimento do desenvolvimento de novas tecnologias no setor, sobre as inovações desenvolvidas por instituições de pesquisa adotadas pela empresa e sobre a introdução de novas espécies.

\section{AS INSTITUICÕES DE PESQUISA}

Do total das instituições dedicadas à pesquisa da pesca na região ou instituições diretamente envolvidas com ela, somente seis realizavam pesquisas especificamente sobre novas espécies e sobre inovações tecnológicas no setor pesqueiro.

A Tabela 1 mostra um sumário das entrevistas. A maior parte das instituições está concentrada nas capitais dos estados. Do total mapeado, 33\% das instituições estavam localizadas em Belém e 36\%, em Manaus. Dessas instituições, foram entrevistadas somente as 12 que realizavam pesquisa na área de pescado, estando a metade localizada no estado do Pará. O número de pesquisadores com mestrado e doutorado é baixo, e poucas são as instituições dedicadas à pesquisa de novas espécies e de novos produtos. Menor ainda é a proporção de pesquisas cujos resultados são adotados pelo setor industrial, segundo essas instituições (Tabela 1).

Tabela 1: Dados estatísticos das instituições pesquisadas.

\begin{tabular}{l|c|c|c|c}
\hline Local & $\begin{array}{c}\text { Instituições } \\
\text { entrevistadas }\end{array}$ & $\begin{array}{c}\text { Possuem } \\
\text { pesquisadores com } \\
\text { especialização } \\
\text { (mestrado e } \\
\text { doutorado) }\end{array}$ & $\begin{array}{c}\text { Pesquisam } \\
\text { novas espécies } \\
\text { e novos } \\
\text { produtos }\end{array}$ & $\begin{array}{c}\text { Tiveram o } \\
\text { resultado da } \\
\text { pesquisa adotado } \\
\text { pelo setor } \\
\text { pesqueiro(*) }\end{array}$ \\
\hline Belém & 5 & 4 & 2 & 1 \\
Santarém & 1 & Não & Não & Não \\
Manaus & 3 & 2 & 2 & 1 \\
Tefé & 1 & 1 & Não & Não \\
Letícia & 2 & 1 & 2 & Não \\
Total & 12 & 8 & 6 & 2 \\
\hline
\end{tabular}

$\left({ }^{*}\right)$ Consideraram-se as pesquisas referentes a novos produtos e/ou a novas espécies.

\subsection{Qualificação dos recursos humanos}

As instituições entrevistadas demonstraram preocupação com a qualificação da mão-de-obra utilizada na pesquisa. Das 12 instituições entrevistadas, oito possuem pesquisadores especializados (com mestrado ou doutorado) e, nas quatro restantes, a qualificação estava sendo 
implementada, ou havia consultores especializados prestando assessoria nos projetos. A qualificação da mão-de-obra foi considerada pelos entrevistados como fundamental para a elaboração de propostas, a liberação de financiamento e a credibilidade dos resultados.

\subsection{Adoção dos resultados pelo setor pesqueiro}

Das 12 instituições pesquisadas, apenas duas tiveram alguns de seus resultados efetivamente aplicados no setor, segundo os entrevistados. Os principais motivos para a baixa introdução das novas pesquisas nos frigoríficos, segundo os entrevistados, foram a falta de interesse nas pesquisas, a resistência dos frigoríficos à realização de novos investimentos, tanto em termos de novos produtos quanto de novas espécies, a falta de mercado para os novos produtos e espécies, a resistência cultural da população à mudança no consumo de espécies tradicionais e o custo associado à implementação de nova tecnologia (equipamentos e treinamento).

Um dos fatores limitantes para a adoção de novas tecnologias desenvolvidas na região é a falta de um sistema institucional de divulgação dos resultados das pesquisas. Além disso, para a absorção dessa tecnologia, é necessária uma assessoria técnica, que nem sempre está disponível. Pequenos negócios, que têm mais contato com essas pesquisas por meio do Serviço Brasileiro de Apoio às Micro e Pequenas Empresas (SEBRAE), muitas vezes não têm o capital para a consultoria necessária e a implantação desses novos produtos.

\subsection{Dificuldades enfrentadas pelas instituições de pesquisa}

As principais dificuldades e limitações enfrentadas pelas instituições entrevistadas na realização das pesquisas estão listadas na Tabela 2. Como pode ser observado pelas respostas, o fator limitante apontado pela maioria das instituições é a falta de recursos financeiros para dar continuidade às pesquisas, seguido da falta de recursos humanos especializados e de melhor infra-estrutura. A lacuna existente na comunicação entre as instituições, sobre as pesquisas desenvolvidas com a comunidade e o setor pesqueiro, também foi considerada um fator limitante importante para a continuidade e a difusão das pesquisas.

Outro fator considerado como agravante no desenvolvimento de novos produtos é o clima úmido da região, porque exerce influência direta sobre os custos de manutenção dos equipamentos utilizados nas pesquisas. 
Tabela 2: Limitações e dificuldades da pesquisa com pescado.

\begin{tabular}{lc}
\hline \multicolumn{1}{c}{ Fatores limitantes } & $\begin{array}{c}\text { Freqüência } \\
\text { (n=12 instituições) }\end{array}$ \\
\hline Falta de recursos financeiros & 6 \\
Falta de recursos humanos & 5 \\
Infra-estrutura inadequada & 4 \\
Falta de comunicação entre instituições e delas com o setor & 4 \\
pesqueiro & \\
Disponibilidade de informação técnica & 3 \\
Custo de aquisição e de manutenção dos equipamentos & 3 \\
utilizados & \\
Resistência cultural & 2 \\
Espaço físico inapropriado & 2 \\
Extensão das áreas a serem estudadas & 2 \\
Clima & 1 \\
Falta de empreendedorismo & 1 \\
\hline
\end{tabular}

\section{AS INDÚSTRIAS DE PROCESSAMENTO}

\subsection{Introdução de novas espécies de pescado}

Ao longo do tempo, novas espécies de pescado têm sido incorporadas ao setor produtivo pesqueiro. São espécies conhecidas, porém pouco exploradas quando comparadas com as tradicionais. Sua exploração foi uma resposta do setor à redução dos estoques das espécies preferenciais e uma iniciativa natural de buscar e abrir novos mercados.

Nas entrevistas realizadas em 20 frigoríficos do Pará e do Amazonas, as razões mais citadas para a introdução de novas espécies foram a criação de novos nichos de mercado e a diversificação de matériaprima para reduzir a dependência que os frigoríficos tinham em relação às poucas espécies. Outro fator mencionado foi a sazonalidade das principais espécies. Muitas empresas relatam que precisam buscar novas espécies para serem capturadas durante o período de defeso das principais espécies (Tabela 3).

Tabela 3: Razões para a introdução de novas espécies pelos frigoríficos do Pará e do Amazonas (2002) (mais de uma resposta por frigorífico).

\begin{tabular}{lr}
\hline Introduziu novas espécies & $71 \%$ \\
\hline Razões para as empresas introduzirem novas espécies: & $\%$ \\
\hline Atendimento da demanda do mercado & 31 \\
Ampliação de mercado da empresa & 15 \\
Diversificação produtiva da matéria prima & 15 \\
Adaptação à oferta de pescado & 15 \\
Redução do esforço de pesca & 8 \\
Intensificação da pesca industrial & 8 \\
Falta de capital de giro para comprar espécies tradicionais & 8 \\
\hline
\end{tabular}


Ao longo do tempo, as empresas introduziram novas espécies no processamento. No início da década de 70, as principais espécies comercializadas eram em torno de dez, sendo a piramutaba e a dourada as mais importantes, processadas por todos os frigoríficos. As demais espécies, de menor importância, eram oito: pescada amarela, corvina, cação, bagre, pescada branca, surubim, tucunaré e filhote.

Em 2002, embora os frigoríficos estivessem em diferentes estágios no processo de introdução de novas espécies, quase 30 são citadas: piramutaba, dourada, mapará, acará-açu, apapá, bagre, cação, corvina, filhote, surubim, xaréu, pargo, atum, meca, garoupa, gurijuba, tubarão, tucunaré, pescada branca, arraia, jaú, bacu, curimatã, piracatinga, jaraqui, sardinha, pacu e aruanã. Apesar do aumento na variedade, as principais espécies (juntas respondem por mais de $50 \%$ da quantidade explorada) continuam a ser as tradicionais e são comercializadas desde a fundação da empresa tais como piramutaba e dourada.

As espécies foram introduzidas em épocas distintas. Alguns frigoríficos foram pioneiros na busca de novas espécies para processamento e ganharam destaque ao introduzi-las no mercado. Posteriormente, outras empresas mais conservadoras passaram a utilizar novas espécies por causa da concorrência da pesca em relação às espécies tradicionais e como forma de agregar valor àquelas menos valorizadas.

O mapará, por exemplo, começou a ser explorado em 1993 por um frigorífico em Santarém. Tratava-se na época de um pescado que tinha pouca aceitação nos mercados locais, mas que foi utilizado para fazer filé e enviado para mercados fora do Estado do Pará. Esse produto teve boa aceitação no mercado, e posteriormente vários frigoríficos passaram a processá-lo.

Alguns frigoríficos registram tentativas constantes de inserir novas espécies, que nem sempre resultaram em sucesso. O bacu e o mandirá foram introduzidos em 1995, mas apresentaram uma perda no processamento muito acentuada no filetamento (88\%) e foram abandonados, segundos algumas empresas. Também foram feitos alguns experimentos com a cujuba, que era considerada ideal para o preparo de carne moída, hambúrguer e lingüiça de peixe, mas foi abandonada porque a carne preparada não era o foco da empresa em 1996.

Em 2001, uma empresa desenvolveu um corte de filé de arraia mais fino, para consumo, mas não o desenvolveu para comercialização em larga escala. O processamento do acari-bodó, um peixe barato de consumo local, também foi cogitado por uma empresa, mas foi descontinuado, para não se comercializar uma espécie muito consumida pela população local.

Em relação ao contato das empresas com instituições de pesquisa, mais da metade das empresas afirma não ter sido contactada por instituições de pesquisa sobre novos produtos e novas espécies. 
Os frigoríficos buscam uma solução para introduzir novas espécies como uma estratégia para a resolução de problemas de abastecimento e de diversificação de produtos. As diversificações ocorreram em termos tanto de novas espécies como de novos produtos. Entretanto, o levantamento histórico da introdução dessas espécies é complexo, pois os entrevistados nem sempre se lembram quando as espécies entraram no mercado. Os entrevistados têm uma idéia aproximada da data da introdução das principais espécies, mas, quanto às espécies menos relevantes, muitas vezes não sabem precisar a data de entrada do produto na empresa.

\subsection{Introdução de novos produtos}

A introdução de novos produtos no mercado está normalmente associada à busca de maior lucratividade da empresa e à expansão de seus mercados. Os produtos principais e tradicionalmente comercializados pelas empresas são: o pescado eviscerado congelado, o filé de pescado congelado e as postas e os lombos de pescado congelado. Esses produtos são os mais importantes e representam quase a totalidade dos produtos comercializados.

A Tabela 4 mostra a pauta de produtos produzidos em 2002 pelos frigoríficos. Também mostra que, dos produtos tradicionais, um terço dos frigoríficos produzia, principalmente, pescado eviscerado congelado, seguido de filé de pescado congelado, postas e lombo de pescado congelado. A partir de 2000, as empresas passaram a diversificar seus produtos, principalmente os que são baseados no aproveitamento de resíduos no processamento e de espécies de baixo valor econômico.

Várias empresas iniciaram a venda de espinhaço com resíduos de carne e de cabeça de pescado congelado, para supermercados locais. Também foram citados o bolinho, o cubinho e as tiras de pescado como novos produtos. Duas empresas começaram a trabalhar com pele de pescado, e várias citaram esse produto como uma alternativa nova no mercado. Esses produtos são baseados nos resíduos dos produtos atuais (Tabela 4). 
Tabela 4. Novos produtos introduzidos no mercado por frigoríficos no Pará e no Amazonas (2002) (mais de uma resposta por frigorífico).

\begin{tabular}{lc}
\hline Produtos tradicionais & Freqüência \\
\hline Peixe eviscerado congelado & 10 \\
Filé de peixe congelado & 9 \\
Postas e lombo de peixe congelado & 8 \\
Peixe inteiro congelado & 2 \\
\hline Novos produtos & 4 \\
\hline Espinhaço com pouco de carne & 3 \\
Peixe fresco ou eviscerado fresco & 2 \\
Picadinho ou polpa de pescado & 2 \\
Pele de peixe & 3 \\
Fishburguer & 2 \\
Farinha de peixe & 2 \\
Lingüiça de pescado & 1 \\
Peixe desossado & 1 \\
Patê de peixe & 1 \\
Bochecha de garoupa & 1 \\
Polpa de pescado & 1 \\
Óleo de peixe & 1 \\
Grude (não inclui as empresas especializadas nesse produto) & 1 \\
Bolinho, cubinho, costela & \\
\hline
\end{tabular}

Algumas empresas, entretanto, mostraram iniciativas mais efetivas, tanto em termos de um novo produto, como em termos de investimento já feito nesse sentido. Por exemplo, o picadinho de pescado é feito pelas empresas com os resíduos do pescado no processo de filetagem e com a exploração de espécies de pequeno tamanho.

A farinha de pescado voltada para a ração animal também tem surgido como uma alternativa de aproveitamento dos resíduos. Uma empresa com fábrica foi montada para iniciar a produção em escala maior na região de Manaus. Outra iniciativa é a venda do pescado fresco para fora do país, utilizando espécies marinhas.

As empresas que fornecem equipamentos para o desenvolvimento de novos produtos são também grande fonte de informação para a introdução de tecnologia. A motivação da compra do equipamento baseia-se nas informações de terceiros e na necessidade interna da empresa. Essas empresas orientam na compra do equipamento correto, ajustam os equipamentos às necessidades do comprador e assessoram na instalação. Também, a fonte de informação de novos produtos e processos são essas empresas de equipamentos, que repassam informações sobre eventos e novos produtos (Tabela 5). 
Tabela 5: Estratégias de compra de equipamentos dos frigoríficos do Pará e do Amazonas (2002).

\begin{tabular}{lc}
\hline Como compram novos equipamentos: & $\%$ \\
\hline Informações de terceiros & 22 \\
Necessidade da empresa & 18 \\
Workshops & 9 \\
Consultorias com instituições & 9 \\
Convites & 6 \\
\hline Quem assessora a empresa: & 33 \\
\hline Equipe interna & 45 \\
Fornecedores de equipamentos & 11 \\
Consultores & \\
\hline Adequação dos equipamentos: & 43 \\
\hline Equipamentos são adaptados & 57 \\
\hline
\end{tabular}

As principais razões apresentadas pelos frigoríficos para a introdução de novos produtos no mercado foram: o aumento da fatia no mercado (27\%), seguido da busca de diversificação do portfólio de produtos da empresa, da sazonalidade e da exigência do mercado externo. Algumas empresas afirmaram que o investimento em novos produtos aconteceu para aumentar o lucro por meio do aumento da produtividade, aproveitando melhor os resíduos internos dos processos, ou em razão da sazonalidade e da concorrência de espécies tradicionais na região (Tabela 6).

Tabela 6: Razões para a introdução de novos produtos pelos frigoríficos do Pará e do Amazonas (2002) ( $\mathrm{N}=11$ frigoríficos que introduziram novos produtos).

\begin{tabular}{lc}
\hline Razões para introduzir novos produtos & $\%$ \\
\hline Aumento da fatia do mercado & 27 \\
Diversificação dos mercados & 18 \\
Sazonalidade & 18 \\
Mercado externo & 18 \\
Aumento do lucro & 9 \\
Suprir dificuldades financeiras & 9 \\
Concorrência com espécies tradicionais & 9 \\
Necessidade do mercado & 9 \\
\hline Como introduzir novos produtos/espécies: & 27 \\
\hline Pesquisa de mercado & 91 \\
\hline
\end{tabular}

Das empresas visitadas que introduziram novos produtos, apenas três fazem pesquisa de mercado antes de sua introdução (27\%). Muitas relatam que clientes nacionais e internacionais visitam a empresa e 
buscam novos produtos. Algumas utilizam recursos como o Sistema de Atendimento ao Consumidor (SAC) para verificar a aceitação do produto e pesquisar as necessidades do mercado. Os demais frigoríficos alegam investir em mercados já estabelecidos, que são mais seguros em termos de aceitação e demanda, com base em pedidos e contratos de venda direto com os clientes, não necessitando, portanto, de pesquisas de mercado.

\subsection{Novas tecnologias e qualidade dos produtos}

Com base na pesquisa realizada, foi possível fazer um levantamento das modificações ocorridas no setor pesqueiro em termos de tecnologia de beneficiamento, que foram adotadas pelos frigoríficos.

As principais mudanças foram feitas nos procedimentos, buscandose a melhor qualidade dos produtos e dos processos, e a minimização das perdas, tanto nos barcos quanto no beneficiamento do pescado.

Em relação à qualidade dos produtos, o Ministério da Agricultura foi um dos principais responsáveis pelas mudanças, com a introdução em 1995 da Análise de Perigos e Pontos Críticos do Processo (APPCC), programa de controle de qualidade adotado pelos frigoríficos da região e que norteia boa parte dos treinamentos desenvolvidos nas empresas que possuem SIF (Sistema de inspeção Federal). Outro fator responsável pela melhoria na qualidade está ligado aos mercados de exportação (Estados Unidos, Japão e Comunidade Européia), cujas exigências em termos de qualidade vão além das exigidas pelo Ministério da Agricultura e refletem-se em mudanças na conservação e no beneficiamento do peixe da região.

Alguns resultados desse programa e do mercado de exportação são: conscientização de pescadores sobre higiene e sanitização, melhoria nas técnicas de conservação do pescado por camada de gelo (enquanto permanecem nos barcos), redução do período de pesca, alternância de barcos para o descarregamento (evitando-se períodos prolongados de pesca) e utilização de água resfriada durante o beneficiamento do pescado, o que auxilia na sua conservação.

As altas temperaturas registradas na região também prejudicam a conservação do pescado, sendo necessário um cuidado maior no congelamento e o uso de gelo durante a pesca. Em virtude do custo do gelo, muitos frigoríficos financiam seu uso para os pescadores de barcos cadastrados. Nesse caso, o pescador passa a ter a obrigação de comercializar o produto com a empresa que forneceu o gelo.

Não houve alterações significativas em termos de tecnologia nos equipamentos utilizados no beneficiamento do pescado; foram adaptados às condições locais de clima e ao tipo de pescado, mas são 'equipamentos 
padrão' para o setor. Em boa parte das empresas, os equipamentos são os mesmos da época da fundação (cerca de 10 ou 20 anos atrás).

Quanto às novas tecnologias, alguns frigoríficos já tiveram contato com o processo de produção de carne mecanicamente separada (CMS) e promovem pesquisas com esse tipo de equipamento. Dos frigoríficos entrevistados, quatro já conheciam essa tecnologia, mas somente um estava testando o processo. Para a introdução dessas tecnologias, tais frigoríficos tiveram contato direto com fornecedores do equipamento, ou a empresa buscou consultoria de profissionais da área, fora da região.

\section{CONCLUSÃO}

Ao todo, aproximadamente 30 entrevistas foram feitas com pesquisadores de instituições e frigoríficos. Desse total, 12 eram instituições de pesquisa, e somente seis tinham pesquisas sobre novas espécies e inovações tecnológicas no setor pesqueiro; em apenas duas delas, o resultado das pesquisas foi adotado pelos frigoríficos.

Nas instituições, o montante do investimento aplicado em pesquisas variou de acordo com o tipo de instituição (autarquia federal, organização civil, secretaria estadual ou municipal, organização não governamental (ONG) e fundos de financiamento).

A qualificação da mão-de-obra foi considerada pelos entrevistados das instituições como fundamental para a garantia e a liberação de financiamento e a credibilidade dos resultados.

As principais espécies pesquisadas pelas instituições são, em geral, pequenas e de baixo valor comercial: piracatinga, piranambu, reco-reco, bacu, cubiú, mapará, aracu, curimatã, jaraqui, branquinha, atum, piraíba e pacamão.

Entre as instituições pesquisadas, apenas o Instituto Nacional de Pesquisas da Amazônia (INPA) e a Universidade Federal do Amazonas (UFAM) desenvolveram pesquisas sobre novas tecnologias para o beneficiamento do pescado e a inclusão de novos produtos no mercado.

Das 12 instituições pesquisadas, apenas duas relataram que tinham alguns de seus resultados aplicados no setor pesqueiro: o Centro de Pesquisa e Gestão de Recursos Pesqueiros do Litoral Norte (CEPNOR) e a UFAM. Os principais motivos apresentados para a baixa interação com empresas foram a falta de interesse dos frigoríficos em desenvolver novos investimentos e a resistência cultural da população ao consumo de produtos não tradicionais. A falta de recursos financeiros foi considerada, pela maioria das instituições entrevistadas, um fator limitante para a continuidade das pesquisas.

Com relação às indústrias de processamento, dos 18 frigoríficos entrevistados, 12 introduziram novas espécies e 12 introduziram novos 
produtos ao longo dos últimos quatro anos (mais de uma resposta por frigorífico).

Apesar da introdução dessas "novas" espécies (espécies conhecidas, mas pouco exploradas comercialmente), as principais espécies utilizadas pelos frigoríficos continuam a ser as tradicionais, como a piramutaba e a dourada, que correspondem a cerca de $50 \%$ da quantidade processada.

Os principais motivos apresentados para a introdução das novas espécies foram a redução dos estoques pesqueiros das espécies tradicionais, a expansão e a diversificação do mercado, os períodos de defeso, a agregação de valor ao produto final de espécies de baixo valor comercial e a procura de compradores por determinadas espécies. Entre as novas espécies exploradas, foram destacadas pelos frigoríficos: pargo, atum, lagosta, mapará, aruanã, acari, bacu, mandirá, cujuba e arraia.

Os novos produtos não são necessariamente novos para o setor; são novos para a indústria de pescado na Amazônia. Entre os novos produtos, destacam-se a porção de pescado (cabeça e espinhaço), o couro de pescado, o pescado fresco, o pescado congelado em mantas, a costeleta de pescado congelado (espinhaço com um pouco de carne), o fishburguer (hamburguer de peixe), o picadinho de pescado, a carne de pescado moída congelada, a polpa de pescado e a farinha e o óleo de pescado.

Quanto às novas tecnologias, destaca-se o equipamento utilizado para a produção de CMS, utilizado em pesquisas no INPA e na UFAM e implementado, em fase piloto, em um dos frigoríficos entrevistados para desenvolver merenda escolar para o governo estadual.

Nos equipamentos utilizados para o beneficiamento do pescado em produtos tradicionais, não houve alterações de tecnologia. $\mathrm{Na}$ maioria das empresas, os equipamentos ainda são os mesmos da época da inauguração (10 ou 20 anos atrás).

Com relação à difusão e à adoção das pesquisas pela indústria pesqueira, na maioria das entrevistas realizadas, observou-se pouca comunicação entre as instituições de pesquisa e os frigoríficos da região. A maioria dos frigoríficos afirma que não há colaboração entre frigoríficos e instituições de pesquisa e que isso acontece somente quando há interesse do frigorífico em alguma pesquisa em particular. As instituições, por outro lado, alegam falta de interesse dos frigoríficos em investir em novos projetos e afirmam existir certa resistência do setor às mudanças. Essa atitude afeta o desenvolvimento e a inovação do setor pesqueiro, uma vez que as pesquisas desenvolvidas acabam não sendo adotadas pelo setor produtivo (frigoríficos), por serem, na 
maior parte, de cunho teórico, o que acaba por separar ainda mais instituições e frigoríficos.

Tanto as instituições de pesquisa quanto os frigoríficos têm papéis importantes no desenvolvimento e na aplicação de novas tecnologias no setor pesqueiro. É preciso que ambos trabalhem em conjunto, com base nas reais necessidades do setor, procurando definir linhas de pesquisa que devam ser adotadas e que sejam viáveis para que o setor possa vir a beneficiar-se com essas pesquisas e a aprimorar seu desenvolvimento.

\section{AGRADECIMENTOS}

Gostaríamos de agradecer ao setor industrial e às instituições pelas entrevistas. Esta pesquisa foi financiada por: Pró-Várzea, DFID, KfW, GTZ, Banco Mundial, PPG7, e pela Fundação Moore ,WWF e CNPq. 


\section{REFERÊNCIAS}

ALMEIDA, O.; LORENZEN, K.; MCGRATH, D. Commercial fishing sector in the regional economy of the brazilian Amazon. In: Welcomme, R.; Petr, T. (Orgs.). Proceedings of the Second International Symposium on the Management of Large Rivers for Fisheries. 1 ed. Bangkok: FAORegional Office for Asia and the Pacific/RAP Publication, v. 2, p. 15-24, 2004.

ALMEIDA, O.; LORENZEN, K.; MCGRATH, D. A frota comercial pesqueira na Amazônia e o co-manejo no Baixo Amazonas. In: ALMEIDA, O. (Org.). Manejo de pesca na Amazônia. São Paulo: Peirópolis, p. 37-50, 2006.

ALMEIDA, O.; MCGRATH, D. G.; RUFFINO, M. L. The commercial fisheries of the lower Amazon: an economic analysis. Fisheries Management and Ecology, n. 8, p. 253-269, 2001.

BATISTA, V. Distribuição, dinâmica da frota e dos recursos pesqueiros da Amazônia central. 1998. 291 f. Tese (Doutorado em Biologia de Água Doce e Pesca Interior) - Instituto Nacional de Pesquisas da Amazônia e Universidade do Amazonas, Manaus, 1998.

BAYLEY, P.; PETRERE JUNIOR, M. Amazon fisheries: assessment methods, current status and management options. In: DODGE, D. P. (Ed.). Proceedings of the International Large River Symposium. Can. Spec. Publ. Fish. Aquat. Sci., v. 106, p. 385-398, 1989.

FOOD AND AGRICULTURE ORGANIZATION. The state of world fisheries and aquaculture 2006. 2007. Disponível em: <http://www.fao.org>. Acesso em:1 jul. 2007.

INSTITUTO BRASILEIRO DO MEIO AMBIENTE E DOS RECURSOS NATURAIS RENOVÁVEIS. Relatório estatístico da pesca, 1996. Brasília, DF, 1998.

INSTITUTO BRASILEIRO DO MEIO AMBIENTE E DOS RECURSOS NATURAIS RENOVÁVEIS. Relatório estatístico da pesca, 1997. Brasília, DF, 1999.

INSTITUTO BRASILEIRO DO MEIO AMBIENTE E DOS RECURSOS NATURAIS RENOVÁVEIS. Relatório estatístico da pesca, 1998. Brasília, DF, 2000a. 
INSTITUTO BRASILEIRO DO MEIO AMBIENTE E DOS RECURSOS NATURAIS RENOVÁVEIS. Relatório estatístico da pesca, 1999. Brasília, DF, 2000b.

INSTITUTO BRASILEIRO DO MEIO AMBIENTE E DOS RECURSOS NATURAIS RENOVÁVEIS. Relatório estatístico da pesca, 2000. Brasília, DF, 2001.

INSTITUTO BRASILEIRO DO MEIO AMBIENTE E DOS RECURSOS NATURAIS RENOVÁVEIS. Estatística da pesca, 2001. Grandes regiões e unidades da federação. Tamandaré, 2003

INSTITUTO BRASILEIRO DO MEIO AMBIENTE E DOS RECURSOS NATURAIS RENOVÁVEIS. Estatística da pesca, 2004. Grandes regiões e unidades da federação. Brasília, DF, 2005

ISAAC, V. J. Fisheries bycatch in the northern coast of Brazil: an anthology of waste. In: CLUCAS, I.; TEUTSCHER, F. (Ed.). Report and proceedings of FAO/DFID Expert Consultation on Bycatch Utilization in Tropical Fisheries. Beijing, China, September 1998. Chatham, UK: Natural Resources Institute, p. 273-294, 1998.

ISAAC, V. J.; MILSTEIN, A.; RUFFINO, M. L. A pesca artesanal no Baixo Amazonas: análise multivariada da captura por espécie. Acta Amazonica, Manaus, v. 26, n. 2, p. 185-208, 1996.

MCGRATH, D.; CASTRO, F.; FUTEMMA, C.; AMARAL, B.; CALABRIA, J. Fisheries and the evolution of resource management on the Lower Amazon Basin. Journal of Human Ecology, v. 21, n. 2, p. 167-195,1993.

PETRERE JUNIOR, M. Pesca e esforço de pesca no Estado do Amazonas I: esforço e captura por unidade de esforço. Acta Amazonica, Manaus, v. 8, n. 3, p. 439-454, 1978a.

PETRERE JUNIOR, M. Pesca e esforço de pesca no Estado do Amazonas II: locais e aparelhos de captura e estatística de desembarque. Acta Amazonica, Manaus, v. 8, suplemento 2, p. 1-54, 1978b. 